Heaney, R., Hallahan, T., Josev, T., \& Mitchell, H. (2007). Time-Changing Alpha? The Case of Australian International Mutual funds. Australian J ournal of Management, 32(1), 95-112.

(c) The Australian Graduate School of Management

This is pre-copy-editing, author-produced version of an article accepted for publication in The Australian J ournal of Management, following peer review. The definitive published version (see citation above) is located on the article abstract page of the publisher, Sage.

This version was made available in the UWA Research Repository on the $14^{\text {th }}$ of November 2014, in compliance with the publisher's policies on archiving in institutional repositories.

Use of the article is subject to copyright law. 


\title{
Time-Changing Alpha? \\ The Case of Australian International Mutual Funds
}

\author{
Richard Heaney*, Terry Hallahan, Thomas Josev and Heather Mitchell \\ RMIT University, Australia
}

\begin{abstract}
Tests for active management inevitably focus on long periods. Yet, implicit in these tests is the assumption that active management generates a stable excess return. We argue that this assumption is not appropriate for active management where the emphasis is on identifying profitable trading strategies. Consistent with this conjecture, we find evidence of time changing alpha using a sample of Australian international funds over the period from July 1995 to January 2005. Regardless, few international funds show consistent positive excess returns over the period.
\end{abstract}

JEL Code: F21, G11, G23

Key words: international equity funds, time changing alpha

Contact

*Richard Heaney, School of Economics, Finance and Marketing, RMIT University, level 12, 239 Bourke Street, Melbourne, 3000,

Phone: 039925 5905, Fax: 039925 5905,

Email: Richard.Heaney@ rmit.edu.au

\section{Acknowledgements}

We acknowledge the use of Morningstar data and the funding provided by the Melbourne Centre for Financial Studies (Grant 16/2005)

First draft date: 4 April 2006

Second draft date: 12 July 2006

Third draft date: 5 January 2007 


\section{Introduction}

The question of whether mutual funds generate abnormal returns is of considerable importance. While active funds are often accused of churning they have also been described as expensive passive funds, tracking the index and thus providing an expensive form of quasi-indexing (Wooley and Bird, 2003). The finance literature provides evidence both supporting (Wooley and Bird, 2003, Minor, 2001) and questioning (Sharpe, 1991, Bogle, 2002) active mutual fund management.

Further, much of the recent research is based on portfolios constructed specifically to avoid survivorship bias and it is possible that these portfolios may bias tests against identifying active managers. While survivorship bias is important in estimation of average returns, survivorship bias adjusted portfolios tell us very little about the performance of individual active fund managers over shorter horizons. It is possible that fund performance over shorter periods has a greater impact on whether an active manager is maintained or replaced by a large superannuation fund, or a retail investor. More precisely estimated long term average returns earned by a portfolio of funds arbitrarily grouped together to avoid survivorship bias may provide little insight into the performance of actively managed funds. For example, active managers are likely to earn rather lumpy returns. When an active manager engages in timing or selection of undervalued or overvalued securities the payoffs from these strategies will not be realised in a smooth predictable fashion.

This paper models the time changing nature of Australian international mutual fund alpha using individual fund returns. We also estimate alpha for mutual fund portfolios, that are essentially survivorship bias free, for comparison purposes. We 
focus on Australian international funds because this sector is growing rapidly ${ }^{1}$ and because these funds give Australian investors access to international financial markets. International equity fund data is collected for those Morningstar funds that report their percentage of overseas equity investment in the range $90 \%$ to $100 \%$. These funds are clearly international equity funds, regardless of their stated fund product description. There has been dramatic growth in this sector over the last few years and although there are 715 funds that fall within this definition as at January 2005 there are only 74 funds with data starting in July 1995 continuing through to January 2005.

The performance evaluation literature has taken two paths. The first assumes that the find manager maintains their stated portfolio risk over the evaluation period (Carhart, 1997, Grinblatt and Titman, 1989, Jensen, 1968, Sharpe, 1966, Treynor, 1965). The second allows for the possibility that managers actively time the market, changing the nature of the portfolio in line with their view of future market conditions (Treynor and Mazuy, 1966, Henriksson and Merton, 1981). Conditional forms of these tests have also been developed by Christopherson, Ferson and Turner (1999) Ferson and Schadt (1996) and Ferson and Warther (1996) and we apply these models in the performance evaluation of Australian international funds.

We find evidence of superior statistically significant alpha estimates for some of the funds over the study period. While there are periods of statistically significant superior performance in the first half of the sample period there is also evidence of statistically significant inferior performance for many of the funds in the second half. A brief literature review is provided in the following section, with model development

\footnotetext{
${ }^{1}$ The Australian Prudential Regulation Authority (APRA), statistics show that the proportion of total superannuation funds invested in international shares is around $18 \%$ of total assets invested with the general growth in total superannuation investment resulting in an increase in dollars invested in international assets from \$38 billion in June 1996 to \$110 billion in June 2004.
} 
in Section 3 and data described in Section 4. Analysis is described and discussed in Section 5 and conclusions follows in Section 6.

\section{Literature Review}

Funds often argue that they are active portfolio managers and this is generally explained in terms of asset selection and market timing. If this is so then we would expect to see variation in estimated timing and selection parameters over reasonably long periods of time. Asset selection involves the identification of under-valued or over-valued shares irrespective of the market conditions. For an international equity fund this may involve the choice of foreign shares, units in international equity funds or similar investments, taking into account the variation in market conditions arising from differences in tax law, securities regulation, investor protection and accounting standards, for example. Market timing is generally modelled in terms of changing portfolio risk over time according to expectations about future returns in the particular markets and much of the research into market timing has focused on the choice between equity and bonds (Sharpe, 1975). If a fund manager is timing the market then they would hold shares when the share market is predicted to perform strongly and bonds where bond returns are expected to outperform the share market. In the case of international equity portfolios, timing may be undertaken by changing the risk profile through the use of derivatives as well as through changes in asset class allocations. ${ }^{2}$ While market-timing benefits can be considerable (Sharpe, 1975, Chua,

\footnotetext{
${ }^{2}$ Changes to equity exposures may take place either by buying or selling the international shares or through the use of derivatives. For example the combination of a well diversified share portfolio and short share price index futures contracts can create a hedged portfolio that earns the risk free rate of return. Later reversal of the futures contract removes the hedge, leaving the underlying share portfolio (Do, 2002). These changes in exposure could also be attained through buying and selling units in international portfolios that specialise in particular international markets and particular asset categories.
} 
Woodward and To, 1987, Shilling, 1992 and Sy, 1990) the theoretical benefits from market timing noted in the literature depend on market forecasting accuracy.

Tests have been developed to identify selectivity and market timing with perhaps the best-known example being the Treynor and Mazuy (1966) test. The test for market timing in this model is based on the assumption that fund managers who time the market change the fund portfolio beta over time with high beta portfolios more likely during periods when equities are performing strongly. This results in a non-linear relationship between realised portfolio returns and share market returns and so the inclusion of a squared market return variable provides a test for market timing.

Given the nature of international equity investment by Australian funds, some form of the International CAPM seems most appropriate for equity fund performance assessment. We use the single factor international capital asset pricing model (ICAPM) of Solnik (1974 and 1977) due to its widespread use in assessing mutual fund performance. This model is augmented to provide for predictable changes in timing parameters (Ferson and Schadt, 1996 and Ferson and Warther, 1996) initially though predictable change in selection parameters is allowed for in later analysis with the use of the Christopherson, Ferson and Turner (1999) approach.

Ferson and Schadt (1996) and Ferson and Warther (1996) argue that the unconditional estimates provided by the original Treynor and Mazuy (1966) approach are not valid where portfolio expected return and risk change over time. For example, Ferson and Warther (1996) find that unconditional tests identify market timing even in a simple buy and hold portfolio, which is inconsistent with the concept of market timing as a purposeful management activity. They show that proper conditioning of these estimates removes this problem. The model has also been extended to capture predictable variation in alphas as well as in beta by Christopherson, Ferson and 
Turner (1999) which follows on the earlier work of Christopherson, Ferson and Glassman (1998). ${ }^{3}$ There has been little application of this model in the literature though we will also use this approach in total period analysis.

Becker, Ferson, Myers and Schill (1999) further extend the Ferson and Schadt (1996) and Ferson and Warther (1996) model to include the impact of information releases, though the added complexity appears to add little to the test. As a result, we focus on the simpler conditional test proposed by Ferson and Schadt (1996) and Ferson and Warther (1996). While Ferson and Schadt (1996) and Ferson and Warther (1996) apply the simple conditional test to USA data. The test has also been applied to Australian equity funds by Sawicki and Ong (2000), to Australian international equity funds over the 1990s by Benson and Faff (2006), Gallagher and Jarnecic (2004) and Heaney and Josev (2005) and to European mutual funds (Engstrom, 2003). While there is considerable work published on the predictable variation in mutual fund timing ability and some dealing with predictable variation in selection ability there is also some research focusing on the broader question of the time series behaviour of estimated Jensen model parameters. For example, Black, Fraser and Power (1992) analyse mutual fund excess returns after allowing for the time series variation in mutual fund risk. There is also more recent work that specifically models the time series behaviour of Jensen alpha and beta in an attempt to improve forecasting (Mamaysky, Speigel and Zhang, 2005). Both of these approaches use a Kalman Filter though there are other approaches that could be used to capture time series variation.

\footnotetext{
${ }^{3}$ For a detailed review of the literature in this area see Ferson and Qian (2004)
} 


\section{Model used in performance evaluation}

The model used to estimate the expected return for the fund should reflect the investment set that the portfolio manager faces and so we use the Solnik (1974 and 1977) version of the international CAPM (ICAPM) within the Ferson and Schadt (1996), Ferson and Warther (1996) and Christopherson, Ferson and Turner (1999) framework for our initial alpha estimates. ${ }^{4}$ Our application of the conditional models draws directly upon the work of Sawicki and Ong (2000). ${ }^{5}$ The model takes the form: $R P_{t}=\left\{\begin{array}{l}\alpha_{p}+b_{1 p} R M_{t}+\gamma_{p} R M_{t}^{2}+b_{2 p} R M_{t} \times J A N_{t}+b_{3 p} R M_{t} \times J U L_{t} \\ +b_{4 p} R M_{t} \times D / P_{t-1}+b_{5 p} R M_{t} \times S T I_{t-1}+b_{6 p} R M_{t} \times Y C_{t-1}+\varepsilon_{p t}\end{array}\right.$

Where the conditioning variables include a constant, January and July dummy variables $\left(J A N_{t}, J U L_{t}\right)$, the dividend yield at time t-1 $\left(D / P_{t-1}\right)$, the short-term interest rate at time $\mathrm{t}-1\left(S T I_{t-1}\right)$ and the yield curve slope at time $\mathrm{t}-1\left(Y C_{t-1}\right)$. The portfolio risk premium $\left(R P_{t}=R_{p t}-R_{i l t}\right)$ is the difference between the return on the international fund $\left(R_{p t}\right)$ and the risk free interest rate $\left(R_{i l t}\right)$, both expressed in local currency. The world market risk premium $\left(R M_{t}=R_{m t}-R_{i w t}\right)$ is the difference between the return on the world market portfolio of risky assets $\left(R_{m t}\right)$, where each security return is expressed in local currency, and a weighted average interest rate for the world $\left(R_{i w t}\right)$. The $b_{i p}$ parameters are measures of the systematic risk of the fund relative to the market, given the conditioning information. The regression residual term is $\varepsilon_{p t}$ and the investment selection parameter $\left(\alpha_{p}\right)$ and a market timing parameter $\left(\gamma_{p}\right)$ also form part of the model. If the selection parameter is positive

\footnotetext{
${ }^{4}$ The analysis has been replicated using the basic Jensen analysis with little change in the results. ${ }^{5}$ This model has also been applied to Australian international equity funds over the 1990s by Benson and Faff (2006), Gallagher and Jarnecic (2004) and Heaney and Josev (2005) and to European mutual funds (Engstrom, 2003).
} 
$\left(\alpha_{p}>0\right)$ then the fund is said to exhibit superior investment selection ability. If the market timing parameter is positive $\left(\gamma_{p}>0\right)$ then the fund is said to exhibit superior investment timing ability. ${ }^{6}$

To date, there has been little discussion concerning the possibility that the selectivity performance measure, alpha, might change over time in some predictable manner. One exception is the model developed by Christopherson, Ferson and Turner (1999). ${ }^{7}$ This model allows estimation of conditional alpha as well as conditional beta and we focus on the conditional alpha estimates in this paper when applying this approach. This model is essentially an expanded form of the Ferson and Schadt (1996) and Ferson and Warther (1996) model, taking the form:

$$
R P_{t}=\left\{\begin{array}{l}
a_{1 p}+a_{2 p} J A N_{t}+a_{3 p} J U L_{t}+a_{4 p} D / P_{t-1}+a_{5 p} S T I_{t-1}+a_{6 p} Y C_{t-1}+ \\
b_{1 p} R M_{t}+\gamma_{p} R M_{t}^{2}+b_{2 p} R M_{t} \times J A N_{t}+b_{3 p} R M_{t} \times J U L_{t}+ \\
b_{4 p} R M_{t} \times D / P_{t-1}+b_{5 p} R M_{t} \times S T I_{t-1}+b_{6 p} R M_{t} \times Y C_{t-1}+\varepsilon_{p t}
\end{array}\right.
$$

Where, similar to the conditional beta, the conditional alpha is now defined as a function of time.

$$
\alpha_{t}=a_{1 p}+a_{2 p} J A N_{t}+a_{3 p} J U L_{t}+a_{4 p} D / P_{t-1}+a_{5 p} S T I_{t-1}+a_{6 p} Y C_{t-1}
$$

Another approach is the use of a Kalman filter to model the time series variation in the Jensen model parameters (for example Black, Fraser and Power, 1992 and Mamaysky, Speigel and Zhang, 2005) though these models rarely allow for predictable variation in risk such as that proposed by Ferson and Schadt (1996) and Ferson and Warther (1996). In this paper we take a simpler approach, using rolling OLS regressions to capture time variation in model parameters along with the removal

\footnotetext{
${ }^{6}$ While an alternative market timing model is described in Merton (1981) and Henriksson and Merton (1981) we focus on the Treynor and Mazuy (1966) model in this paper as the two methods generally provide similar results (Engstrom, 2003 and Ferson and Schadt, 1996).

${ }^{7}$ We thank the anonymous reviewer for suggesting this approach to capturing predictable variation in alpha over time.
} 
of predictable variation in risk using the Ferson and Schadt (1996) and Ferson and Warther (1996) model. To some extent this model falls mid-way between the simple Kalman filter models appearing in the literature and the more complex, data intensive conditional models. There is a trade off between model choice and sample size in this analysis because of the limited data that is available. As a result we do not attempt to run rolling Christopherson, Ferson and Turner (1999) based regressions because of the very large number of parameters that must be estimated for this approach, though this approach is of interest for future research as more data becomes available on international mutual fund performance.

\section{Data}

International equity funds are defined as those funds that invest $90 \%$ or more of available funds in international equities as at January 2005. There are 715 funds in the initial list of funds as at January 2005 that meet the foreign investment requirement but most of these funds came into existence after 2000, providing little time series data for individual fund analysis. As a result we use two types of data for analysis. The first focuses on the 74 individual funds with a full set of monthly data over the period July 1995 to Jan 2005. Analysis of the surviving funds, while important, begs the question of survivorship bias (Brown, et al, 1992). We construct two portfolios to account the impact of survivorship bias. The first is an equally weighted portfolio of all available funds each month. The second consists of a value weighted portfolio of all available funds each month. A third portfolio is also constructed and this is an equally weighted portfolio of the 74 surviving funds. It provides a base case for comparison with our survivorship bias free portfolios. 
Returns, net of the risk free rate, are calculated for the 74 individual funds and for the portfolios of funds. As indicated in Table 1, the individual funds in the sample report negative excess returns for the period of $-0.13 \%$ per month though there is considerable volatility across the funds with an average standard deviation of $3.93 \%$ per month. The distribution of the return statistics across the individual funds can be seen from the median, maximum and minimum, which are also reported. The performance of the three portfolios is similar to the reported averages for the individual funds though, as might be expected, the estimates are less dispersed. We have also estimated autocorrelation coefficients for the individual funds and for the portfolios and we find that the portfolio autocorrelation coefficients are somewhat higher (these are available from the authors on request).

[Insert Table 1 about here]

The fund risk premia and world equity market risk premia are required for implementation of the International CAPM though the Ferson and Schadt (1996) and Ferson and Warther (1996) model requires additional conditioning variables to capture predictable variation in fund beta. The conditioning variables used in this paper include a January dummy variable $\left(J A N_{t-1}\right)$, a July dummy variable $\left(J U L_{t-1}\right)$, the dividend yield $\left(D / P_{t-1}\right)$, a short-term interest rate $\left(S T I_{t-1}\right)$ and the yield curve slope $\left(Y C_{t-1}\right)$. The short-term interest rate and the dividend yield are expressed as continuously compounding returns per month. Summary statistics are reported in Table 2.

[Insert Table 2 about here]

While there are commercially available dividend yield series these are generally smoothed, reflecting the average dividend for the previous 12 months as a percentage of the beginning of period price. To avoid induced serial correlation 
arising from such measures, a dividend yield series is calculated from the MSCI world total return and price indices. Estimates of short-term interest rates are required for calculation of excess returns for individual funds and for the market portfolio proxies. The world risk free rate is approximated using an equally weighted average of the 3-month interest rates obtained from the OECD for the USA, Japan and Europe expressed as a rate per month. The yield curve slope estimates are calculated by taking the difference between the average OECD 10 year rate per annum and the average OECD 3-month rate per annum for the USA, Japan and Europe. The risk premia for the market portfolio of risky assets is the difference between the return on the local currency MSCI world total return index and the world risk free rate estimated by averaging the short-term interest rates for the USA, Europe and Japan as supplied by the OECD.

\section{Time Variation in Alpha Estimates}

We use rolling regressions to capture the time variation in the fund alphas over the sample period. A key decision is the selection of an estimation window. If the window is too large the analysis may ignore important time series variation in the alphas and it will also result in exclusion of funds that have insufficient data. If the window is too short then there may be some doubt cast on the accuracy of the estimates. As a result we use rolling 24 month and rolling 36 month regressions to capture the time variation in alpha in this study. The first alpha estimate is calculated using the monthly observations from July 1995 to June 1997 for the 24 month case or from July 1995 to June 1998 for the 36 month case. The next estimate of alpha is calculated using the monthly observations from August 1995 to July 1997 (24 month regression) or from August 1995 to July 1998 (36 month regression) respectively and 
this is continued month-by-month until the end of the sample. This procedure gives rise to 91 24-month based alpha estimates (79 36-month based alpha estimates) for each of the individual funds and for the three fund portfolios. In all cases we report the Ferson and Schadt (1996) and Ferson and Warther (1996) alpha estimates. Jensen alphas were also calculated though there was little difference in the final results and so they are not reported separately here.

\subsection{Analysis of Individual Funds}

Figure 1, Panel A, provides a graph of the time series variation in the rolling alphas and their associated t-statistics. ${ }^{8}$ Each fund is allocated a line in the graph and so the more that individual fund performance coincides the darker the graph. There is considerable dispersion in the alpha estimates prior to 2000, particularly around the Asian crisis, which began late in 1997 . This is due to a comparatively small group of nine funds that concentrate on investment in the Asian region. The unusual variation in the later part of the figure is also explained by these same funds. Regardless, the bulk of the funds follow a pattern of positive alphas in the first half of the period followed by negative alphas in the second half of the period. The time variation in the t-statistics calculated for the alphas is reported in Panel B of Figure 1. There is clear evidence of statistically significant variation in the t-statistics estimated for the rolling alphas. There are statistically significantly positive t-statistics in the early part of the study period and statistically significantly negative t-statistics in the later part of the study period.

[Insert Figure 1 about here]

\footnotetext{
${ }^{8}$ Rolling Jensen Alpha estimates were also estimated though these are not reported separately as there is little difference in the results. The choice of 24 or 36 month rolling alpha has little impact on the results.
} 
We calculate summary statistics for the alpha estimates and accompanying t-statistics and these are reported in Table 3, with the individual fund statistics reported in Panel A and the fund portfolio statistics reported in Panel B. There is considerable variation in both the rolling alpha estimates and accompanying t-statistics. The alphas are estimated using both 24-month and 36-month rolling windows and the summary statistics refer to these estimates obtained for each of the 74 surviving individual funds. The average of the estimated mean alphas and accompanying average of the alpha t-statistics appear little affected by the choice of estimation window though there is some variation in the median and the global maximum alpha estimates. While the average alpha is negative for the period the volatility of these estimates is of particular interest. The global maximum alpha is statistically significant $(t=3.72$ for the 24 month window and $t=3.28$ for the 36 month window $)$ and so is the global minimum alpha $(\mathrm{t}=-4.54$ for the 24 month window and $t=-4.17$ for the 36 month window). Further, the standard deviation in these estimates is quite large, consistent with there being a number of funds that have earned statistically significant positive and negative alphas over the period.

[Insert Table 3 about here]

To gain some further insight into this variation we calculate the number of funds reporting at least one statistically significant negative alpha (64 for the 24 month window and 63 for the 36 month window), the number of funds reporting at least one statistically significant positive alpha (29 for the 24 month window and 16 for the 36 month window) and the number of funds reporting at least one statistically significant negative alpha and at least one statistically significant positive alpha (27 for the 24 month window and 15 for the 36 month window). As is evident from Figure 1 a fund could report both positive and negative alpha estimates over the study 
period and many of the funds in the sample exhibit this behaviour. The positive alphas are clustered in the first half of the study period as can be seen in Figure 1 and in the reduction in the number of statistically significant alphas that are identified when using the longer 3 year estimation horizon. It is important to note that most of the funds that exhibited positive alphas in the first part of the study also exhibited negative alphas in the second part of the study.

\subsection{Analysis of Fund Portfolios}

Panel B of Table 3 provides summary statistics for the three fund portfolios, the equally weighted portfolio of surviving funds, the equally weighted portfolio of all available funds and the value weighted portfolio of all available funds. Statistics are reported for both the rolling alpha estimates and the alpha t-statistics using the 24-month window and the 36-month window. While the two equally weighted funds are similar in terms of mean alpha, the more comprehensive portfolio consisting of all available funds is considerably more volatile both in terms of standard deviation and the minimum and maximum values. The value weight portfolio, consisting of all funds, earns a smaller loss per month over the period but it is more volatile than either of the two equally weighted portfolios.

The creation of portfolios tends to average out exceptional performance and this is certainly the case with these three portfolios. While, there are few periods where statistically significant positive alphas are reported in Panel B (see the $\mathrm{t}$-statistics in the lower part of the table) there is around $20 \%$ of the estimated alphas that are statistically significantly negative and these occur in the later half of the study period. Thus, when we form portfolios of the funds, the strong performance of 
individual funds, either positive or negative, (see Panel A) tends to be averaged out over the sample.

\subsection{Full period analysis}

Thus, there is evidence of time variation in performance over the study period for a proportion of the funds and for part of the study period these estimates are statistically significant. While the analysis has focused on time variation in individual fund alpha using rolling regressions, it is important also to look at full period tests of alpha, particularly when allowance is made for predictable changes in alpha (Christopherson, Ferson and Turner, 1999). The results from the full period analysis are quite different from those reported above as they focus either on the 74 individual funds that survive the whole period or on equally weighted or value weighted portfolios of all available funds.

Unconditional alphas are estimated for the 74 surviving funds and the fund portfolios using the data for the full study period. These methods are not suited to identifying time variation in alpha because they focus on the average excess return that is earned over the period, forcing time variation in alpha into the residual term. Regardless, we find that the estimated unconditional alphas were generally negative for the surviving funds as well as for the fund portfolios and, in a number of cases, the alphas were statistically significantly negative. For example, when we applied the Ferson and Schadt model to estimate alphas for the three fund portfolios using the full period we find that both the equally weighted portfolios exhibit statistically significant negative alphas $(\mathrm{t}=-2.03$ for the equally weighted 74 survivor portfolio and $t=-1.96$ for the equally weighted all fund portfolio). The alpha coefficient is not statistically significant for the value weighted portfolio. It should be noted that these 
full sample results fail to capture the considerable variation in individual fund alpha identified in Figures 1 and 2.

Further, to assess the impact of predictable changes in alpha, we apply the Christopherson, Ferson and Turner (1999) approach to the three different fund portfolios and we find that the excess return over the full period is not statistically significant. The alphas (t-statistic) were $0.21(0.18)$ for the 74 survivors portfolio, $-0.02(-0.1)$ for the equally weighted portfolio of all funds available in each month and $0.47(0.36)$ for the value weighted portfolio consisting of all funds available in each month. It appears that much of the statistically significant variation in full period unconditional estimates of alpha for these portfolios of funds arises from the failure to properly condition the data for predictable variation in alpha (Christopherson, Ferson and Turner, 1999). A useful extension to this study would be the estimation of rolling regressions based on the much larger Christopherson, Ferson and Turner (1999) model. It is possible that some of the variation in alpha that we observed in our rolling regressions is predictable, though we do not attempt to address this question here due to data limitations.

In this section we create fund portfolios and test for the possibility of statistically significant alphas for the full sample period. While there is some evidence of statistically significant negative alphas when using unconditional alpha estimates, the statistical significance disappears where conditional alpha estimates are used.

\subsection{Sensitivity issues}

There is some question about the use of Australian dollar returns for funds, consistent with the Solnick International CAPM. To gauge the impact of the use of 
local currency returns for both the funds and the MSCI world index we restate the Australian international fund returns in terms of USD returns and choose the USD version of the MSCI world index and repeat the analysis. As might be expected there is some change in the time variation in the rolling alpha estimates with losses in the early part of the study followed by profits in the later part of the study. Nevertheless, there is still evidence of periods where funds exhibit statistically significant positive alphas and periods where statistically significant negative alphas are evident. ${ }^{9}$

A cursory analysis of Figure 1 suggests the existence of a small number of funds that behave quite differently from the remainder of the funds. As a result we separate out the nine funds with a stated Asian focus and two funds with a stated bias towards the USA or Europe to get a better idea of how the remaining funds, those that describe themselves as global or international funds, have performed over the period. We graph the 24-month rolling alpha estimates and associated t-statistics in Figure 2. The general trend in the international fund alphas is somewhat clearer than in Figure 1. While the mutual fund alphas are negative prior to 1998, by June 1998 most of the funds show evidence of positive alphas and this continues to around June 2001. From there on, the majority of the funds exhibit negative alphas. A similar trend is evident in the rolling t-statistics graphed in Panel B of Figure 2. Alpha is not constant over time for this set of funds though very few of the funds in this sample are able to maintain positive alphas over the sample period.

[Insert Figure 2 about here]

Analysis of individual fund alphas suggests the possibility of instability in alpha over the study period. To get a better sense of the stability of the full period Ferson and Schadt alpha and Jensen alpha estimates we take an arbitrary 50\% break

\footnotetext{
${ }^{9}$ Separate results from this analysis are available on request.
} 
point and test for change in the alpha estimates using a dummy variable with ones for the months from July 1995 to February 2000 and zero otherwise. A t-test on this dummy variable provides a rough test for stability of alpha over the study period and the $\mathrm{t}$-statistics are calculated for each of the 74 funds in the sample with a full set of monthly returns over the study period (See Table 4). At the 5\% (10\%) level of significance there is a statistically significant change in alpha for 30 (49) of the 74 funds where the Jensen alpha is used and statistically significant change in alpha for 38 (51) of the 74 funds where the Ferson and Schadt alpha is used. The nine Asian funds all fall into the group of funds where there is no evidence of a statistically significant change in alpha. This is not surprising given the quite different time series behaviour of the alphas generated by the Asian funds.

\section{Conclusion}

The returns to selectivity, or alpha, could be an important source of returns for a fund manager but there has been little work that focuses on whether fund alpha varies over time. The results from rolling regressions that are reported in this study suggest that the alphas earned by the international funds are not constant over time. This is apparent whether Solnick's local currency based international capital asset pricing model is used or whether all returns are converted to USDs; though it should be noted that the actual time variation in alphas does vary with the currency choice as might be expected.

Graphical analysis, based on Solnick's local currency based model, shows that over the last 10 years there have been considerable periods of time when the individual global/international fund rolling alphas suggest that the funds have out performed the MSCI world index after adjustment for risk (and for the possibility of 
market timing). There are also considerable periods when this group of funds underperformed relative to the world index.

Unconditional and conditional estimates of mutual fund portfolio alphas were also calculated over the full sample period. While there was some evidence of statistically significant negative unconditional alphas for the equally weighted portfolios this was not apparent for the value weighted portfolio. Conditional alpha estimates were not found to be statistically significantly from zero regardless of the portfolio construction technique used. Thus, consistent with most studies reported in the literature, there is little evidence of long run average excess returns.

The key finding of this paper is the identification of considerable time variation in individual fund alpha despite average excess returns across the sample being close to zero for the full period. Perhaps the regular assessment of the performance of fund managers by investors is a sensible strategy if it results in the use of particular fund managers who are earning excess returns at the time. It appears from the analysis reported here that both positive excess returns and negative excess returns are transient states of the world for most of the funds in our sample. Further, excess return estimates for most of the sample tend to move together over time. While further analysis of possible explanations for this result are beyond the scope of this paper herding provides one explanation, though we leave analysis of this possibility to future research. Another topic for future research is the application of the Christopherson, Ferson and Turner (1999) in rolling regressions to assess the impact of predictable variation on the time series behaviour of excess returns. 


\section{References}

Becker, C., Ferson, W., Myers, D. and Schill, S., 1999, Conditional Market Timing with Benchmark Investors, Journal of Financial Economics, 52, 663-682.

Benson, K. L. and Faff, R. W., 2006, Conditional Performance Evaluation and the Relevance of Money Flows for Australian International Equity Funds, Pacific-Basin Finance Journal, 14, 231-249.

Black, A., Fraser, P. and Power, D., 1992, IK Unit Trust Performance 1980-1989: A Passive Time-Varying Approach, Journal of Banking and Finance, 16, 1015-1033.

Bogle, J. C., 2002, An Index Fund Fundamentalist, Journal of Portfolio Management, 28, 31-38.

Brown, S.J., Gortzmann, W., Ibbotson R.G. and Ross, S.A., 1992, Survivorship Bias in Performance Studies, Review of Financial Studies, 5, 553-580.

Carhart, M.M., 1997, On Persistence in Mutual Fund Performance, Journal of Finance, 52, 57-82.

Christopherson, J. A., Ferson, W. E. and Glassman, D. A., 1998, Conditioning Manager Alphas on Economic Information: Another Look at the Persistence of Performance, Review of Financial Studies, 11, 111-142.

Christopherson, J. A., Ferson, W. E. and Turner, A. L., 1999, Performance Evaluation Using Conditional Alphas and Betas, Journal of Portfolio Management, 26, 59-72.

Chua, J. H., Woodward, R. S. and To, E. C., 1987, Potential Gains from Stock Market Timing in Canada, Financial Analyst Journal, 43, 50-56.

Do, B. H., 2002, Relative Performance of Dynamic Portfolio Insurance Strategies: Australian Evidence, Accounting and Finance, 42, 279-296.

Engstrom, S., 2003, Costly Information, Diversification and International Mutual Fund Performance, Pacific-Basin Finance Journal, 11, 463-482.

Ferson, W. E. and Qian, M., 2004, Conditional Performance Evaluation, Revisited, Research Foundation of CFA Institute, 1-85.

Ferson, W. E. and Schadt, R. W., 1996, Measuring Fund Strategy and Performance in Changing Economic Conditions, Journal of Finance, 51, 425-461.

Ferson, W. E. and Warther, V. A., 1996, Evaluating Fund Performance in a Dynamic market, Financial Analysts Journal, 52, 20-28.

Gallagher, D. R. and Jarnecic, E., 2004, International Equity Funds, Performance, and Investor Flows: Australian Evidence, Journal of Multinational Financial Management, 14, 81-95. 
Grinblatt, M., and Titman, S., 1989, Mutual Fund Performance: An Analysis of Quarterly Portfolio Holdings, Journal of Business, 62, 393-416.

Heaney, R. A. and Josev, T., 2005, Australian International Equity Fund Performance, RMIT Working paper, 1-29.

Henriksson, R. D. and Merton, R. C., 1981, On Market Timing and Investment Performance II: Statistical Procedures for Evaluating Forecasting Skills, Journal of Business, 54, 513-533.

Jensen, M., 1968, The Performance of Mutual Funds in the Period 1954-1964, Journal of Finance, 23, 389-416.

Mamaysky, H., Speigel, M. and Zhang, H., 2005, Improved Forecasting of Mutual Fund Aplhas and Betas, Yale International Centre for Finance, Yale ICF Working Paper No. 04-23, 1-36.

Merton, R. C., 1981, On Market Timing and Investment Performance I: An Equilibrium Theory of Value for Market Forecasts, Journal of Business, 54, 363-406.

Minor, D. B., 2001, Beware of Index Fund Fundamentalists, Journal of Portfolio Management, 27, 45-50.

Sawicki, J and Ong, F., 2000, Evaluating Managed Fund Performance Using Conditional Measures: Australian Evidence, Pacific-Basin Finance Journal, 8, 505528.

Sharpe, W. F., 1966, Mutual Fund Performance, Journal of Business, 39, Supplement on Security Prices, 119-38.

Sharpe, W. F., 1975, Likely Gains From Market Timing, Financial Analyst Journal, 31, 60-69.

Sharpe, W. F., 1991, The Arithmetic of Active Management, Financial Analyst Journal, 47, 7-10.

Shilling, A. G., 1992, Market Timing: Better Than A Buy-And-Hold Strategy, Financial Analyst Journal, 1992, 48, 46-50.

Solnik, B., 1974, The International Pricing of Risk: An Empirical Investigation of the World Capital Market Structure, Journal of Finance, 29, 365-378.

Solnik, B., 1977, Testing International Asset Pricing: Some Pessimistic Views, Journal of Finance, 32, 503-512.

Sy, W., 1990, Market Timing: Is It A Folly?, Journal of Portfolio Management, 16, 11-16.

Treynor, J. L., 1965, How to Rate Management of Investment Funds, Harvard Business Review, 43, 63-75. 
Treynor, J. and Mazuy, F., 1966, Can Mutual Funds Outguess the Market?, Harvard Business Review, 44, 131-136.

Wooley, P., and Bird, R., 2003, Economic Implications of Passive Investing, Journal of Asset Management, 3, 303-312. 
Table 1

Descriptive Statistics for Returns Net of the Risk Free Rate

\begin{tabular}{lcccccc}
\hline & $\begin{array}{c}\text { Individual } \\
\text { Survivors } \\
\text { Mean }\end{array}$ & $\begin{array}{c}\text { Individual } \\
\text { Survivors } \\
\text { Median }\end{array}$ & $\begin{array}{c}\text { Individual } \\
\text { Survivors } \\
\text { Std.dev. }\end{array}$ & $\begin{array}{c}\text { All } \\
\text { Survivors } \\
\text { Portfolio }\end{array}$ & $\begin{array}{c}\text { All Funds } \\
\text { Equal Wgt. } \\
\text { Portfolio }\end{array}$ & $\begin{array}{c}\text { All Funds } \\
\text { Value Wgt. } \\
\text { Portfolio }\end{array}$ \\
\hline Mean & -0.1298 & -0.1123 & 0.1799 & -0.1298 & -0.1475 & -0.0070 \\
Median & 0.0322 & -0.0119 & 0.3563 & 0.4023 & 0.4089 & 0.2656 \\
Std. dev. & 3.9360 & 3.7137 & 1.0481 & 3.2649 & 3.4584 & 3.6244 \\
Max. & 9.7348 & 8.0104 & 4.2004 & 7.4729 & 7.2472 & 8.2060 \\
Min. & -11.8931 & -10.4510 & 4.6577 & -9.3298 & -9.5079 & -9.6111 \\
\hline
\end{tabular}

Note: Returns are calculated for the individual funds and the Mean, median and Standard deviation are reported for each of the descriptive statistics calculated for each of the 74 individual funds. Portfolio returns are calculated for the surviving funds as well as for all available funds. While the surviving fund portfolio is equally weighted the all fund portfolio is constructed with both equal weighting and value weighting. Returns are continuously compounded rates of return per month expressed as percentages per month net of the 30-day bank accepted bill yield for the month. There are 115 monthly observations in the study period from July 1995 to January 2005. The descriptive statistics are reported described in column 1 with mean, median, std. dev. (standard deviation), max. (maximum) and min. (minimum return). 
Table 2

Descriptive Statistics for Equity Market Indices, Interest Rates and Conditioning Information

\begin{tabular}{lrrrrr}
\hline & \multicolumn{1}{c}{ Mean } & \multicolumn{1}{c}{ Median } & Std. Dev. & Maximum & \multicolumn{1}{c}{ Minimum } \\
\hline$R M$ & 0.4415 & 1.1430 & 4.3282 & 7.7764 & -15.7619 \\
$R M^{2}$ & 18.7655 & 8.0035 & 30.9092 & 248.4380 & 0.0002 \\
$D / P$ & 0.1518 & 0.1445 & 0.0475 & 0.3064 & 0.0615 \\
$S T I$ & 0.2228 & 0.2606 & 0.0854 & 0.3711 & 0.0852 \\
$Y C$ & 1.4171 & 1.5484 & 0.6303 & 2.4597 & -0.0076 \\
\hline
\end{tabular}

Note: All returns are continuously compounded rates of return per month expressed as percentages per month. These variables are the equity market indices, interest rates and conditioning information used in performance evaluation. The data spans the period from July 1995 to January 2005. RM is the world market risk premium and is the difference between the return on the local currency MCSI world total return index and a world risk free rate estimated by averaging the short-term interest rates for the USA, Europe and Japan as supplied by the OECD. RM ${ }^{2}$ is the world market risk premium squared and this is included to capture market timing. $\mathrm{D} / \mathrm{P}$ is the monthly dividend yield estimated from the monthly MCSI world index total return and price indices. STI is the average of the short-term interest rates for the USA, Europe and Japan as supplied by the OECD expressed as a return. YC is the difference between the average of the long-term interest rates for the USA, Europe and Japan as supplied by the OECD less STI. 
Table 3

\section{Descriptive Statistics for the Ferson and Schadt Rolling Alpha Estimates}

\section{Panel A: Individual Funds}

\begin{tabular}{lcccc}
\hline & $\begin{array}{c}\text { Average Rolling } \\
\text { Fund Alpha } \\
\text { (24 months) }\end{array}$ & $\begin{array}{c}\text { Average Rolling } \\
\text { Fund Alpha } \\
\text { t-statistic } \\
(24 \text { months })\end{array}$ & $\begin{array}{c}\text { Average Rolling } \\
\text { Fund Alpha } \\
\text { (36 months) }\end{array}$ & $\begin{array}{c}\text { Average Rolling } \\
\text { Fund Alpha } \\
\text { t-statistic } \\
\text { (36 months) }\end{array}$ \\
\hline Avg. Mean & -0.2454 & -0.4268 & -0.2567 & -0.4619 \\
Avg. Median & -0.2497 & -0.3095 & -0.1546 & -0.2220 \\
Avg. Std. dev. & 0.9101 & 1.2348 & 0.7013 & 1.2292 \\
Global Max. & 3.7174 & 3.7244 & 1.7537 & 3.2820 \\
Global Min. & -6.1534 & -4.5422 & -5.1190 & -4.1672 \\
No. sig. +ve & & 29 & & 16 \\
No. sig. -ve & & 64 & & 63 \\
No. both +ve \& -ve & & 27 & & 15 \\
\hline Note: Ferson & & & & \\
\hline
\end{tabular}

Note: Ferson and Schadt (1996) and Ferson and Warther (1996) alpha estimates and associated t-statistics are calculated for each of the funds using a 24-month (36-month) rolling window and this gives 91(79) separate alpha estimates for each fund. Descriptive statistics are averages across all 74 funds for the mean (Avg. Mean), the median (Avg. Median) and the standard deviation (Avg. Std. Dev.) while the maximum (Global Max.) and minimum (Global Min.) are global values for all funds. For example the mean alpha is calculated for each of the 74 funds and the average of these means is the Avg. Mean reported above. Further, the Global Max. alpha is the maximum of the maximum alphas that are calculated for each of the 74 funds. No. sig. +ve is the number of funds with at least one statistically significant positive alpha estimate. No. sig. -ve is the number of funds with at least one statistically significant negative alpha estimate. No. both +ve \& -ve is the number of funds with at least one statistically significant negative alpha estimate as well as at least one statistically significant positive alpha estimate. There are 74 funds in the sample.

\section{Panel B: Fund Portfolios}

\begin{tabular}{lcccccc}
\hline & $\begin{array}{c}\text { Surviving } \\
\text { Funds } \\
(24 \text { mths })\end{array}$ & $\begin{array}{c}\text { Surviving } \\
\text { Funds } \\
(36 \text { mths })\end{array}$ & $\begin{array}{c}\text { All Funds } \\
\text { Equal } \\
\text { Weighted } \\
(24 \text { mths })\end{array}$ & $\begin{array}{c}\text { All Funds } \\
\text { Equal } \\
\text { Weighted } \\
(36 \text { mths })\end{array}$ & $\begin{array}{c}\text { All Funds } \\
\text { Value } \\
\text { Weighted } \\
(24 \text { mths })\end{array}$ & $\begin{array}{c}\text { All Funds } \\
\text { Value } \\
\text { Weighted } \\
(36 \text { mths })\end{array}$ \\
\hline Alpha & & & & & & \\
Mean & -0.2454 & -0.2567 & -0.2322 & -0.2462 & -0.1525 & -0.1304 \\
Median & -0.3054 & -0.1646 & -0.1860 & -0.0430 & -0.1278 & 0.0229 \\
Std. dev. & 0.5550 & 0.4054 & 0.7045 & 0.5333 & 0.8383 & 0.6482 \\
Max. & 1.1992 & 0.3577 & 1.4297 & 0.5023 & 1.6002 & 0.8007 \\
Min. & -1.2089 & -1.0302 & -1.4458 & -1.2143 & -1.5939 & -1.2591 \\
t-statistics & & & & & & -0.4840 \\
Mean & -0.5878 & -0.7112 & -0.5820 & -0.6782 & -0.4471 \\
Median & -0.5526 & -0.3481 & -0.3291 & -0.0941 & -0.1975 & 0.0421 \\
Std. dev. & 1.1222 & 1.1063 & 1.3468 & 1.3562 & 1.5138 & 1.5227 \\
Max. & 1.8006 & 0.8532 & 1.9646 & 1.1157 & 2.0908 & 1.6484 \\
Min. & -2.8248 & -2.8690 & -3.3642 & -3.2110 & -3.5204 & -3.3816 \\
No. sig.+ve & 0 & 0 & 1 & 0 & 1 & 0 \\
No. sig. -ve & 14 & 18 & 17 & 22 & 19 & 23 \\
\hline
\end{tabular}

Note: Ferson and Schadt (1996) and Ferson and Warther (1996) alpha estimates and associated tstatistics are calculated for the fund portfolios using a 24-month (36-month) rolling window and this gives 91(79) separate alpha estimates for each portfolio. Descriptive statistics include the mean, the median, the standard deviation (Std. Dev.), the maximum (Max.) and the minimum (Global Min.). No. sig. +ve is the number of statistically significant positive alpha estimates. No. sig. - ve is the number of statistically significant negative alpha estimates. Note that these statistics refer to the time series data for each of the portfolios of funds and so there is a maximum of 91 (79) alpha estimates for the 24 (36) month based estimates. 


\section{Table 4}

\section{Summary Statistics for Change in Alpha}

Ferson and Schadt Alpha Estimates Summary Based on the 74 Surviving Funds

\begin{tabular}{lrrrrrrr}
\hline & Average & Median & Max & Min & Std Dev & $\mathrm{N}>5 \%$ & $\mathrm{~N}>10 \%$ \\
\hline Change in alpha & 0.8396 & 0.9677 & 1.7304 & -0.9563 & 0.5069 & & \\
Standard Error & 0.5353 & 0.4646 & 1.2902 & 0.2301 & 0.2083 & & \\
t-statistic & 1.7999 & 2.0023 & 3.7305 & -0.9444 & 0.9429 & 39 & 51 \\
\hline
\end{tabular}

Note: The alphas are estimated using the full sample period from July 1995 to January 2005. Change in alpha is the parameter value for the dummy variable with a value of one for the period from July 1995 to January 2001 and zero for the remainder of the period from February 2001 to January 2005. Ordinary least squares regression is used for each of the estimates. Descriptive statistics include the mean, median, standard deviation (Std.dev.), maximum (Max.) and minimum (Min.) and these are calculated for the change in alpha estimates for the 74 funds in the sample for the Ferson and Schadt alpha estimates. $\mathrm{N}>5 \%$ refers to the number of funds where the $\mathrm{t}$-statistic is statistically significant at the $5 \%$ level of significance and $\mathrm{N}>10 \%$ refers to the number of funds where the t-statistic is statistically significant at the $10 \%$ level of significance. 


\section{Figure 1}

Ferson and Schadt Alphas Calculated with a 24-Month Moving Window Over the Period July 1995 - January 2005 Using 74 Surviving Funds

Panel A: Rolling alpha coefficients

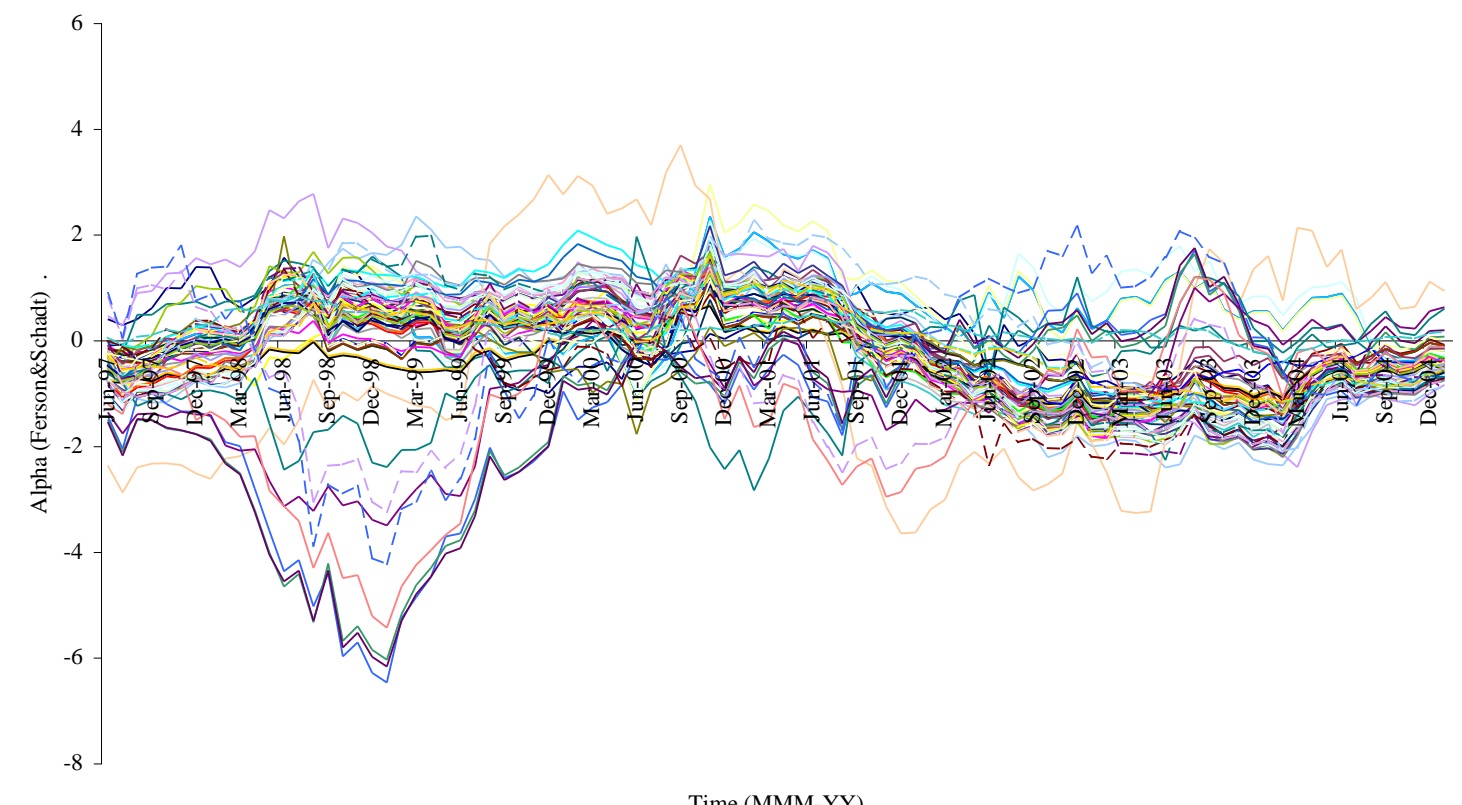

Panel B: Rolling alpha t-statistics

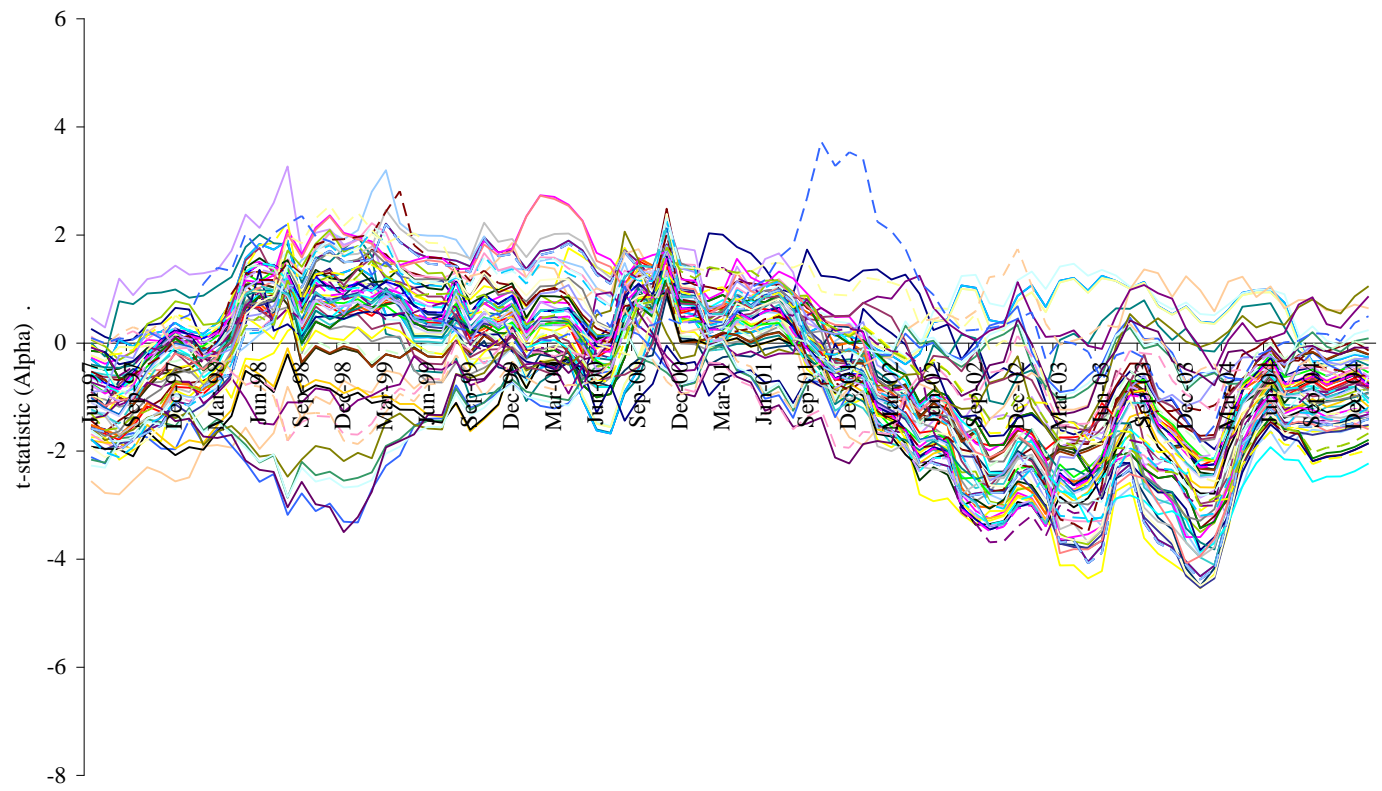

Time (MMM YY) 
Figure 2

Ferson and Schadt Alphas Calculated with a 24-Month Moving Window Over the Period July 1995 - January 2005 Using Global or International Funds

Panel A: Rolling alpha coefficients

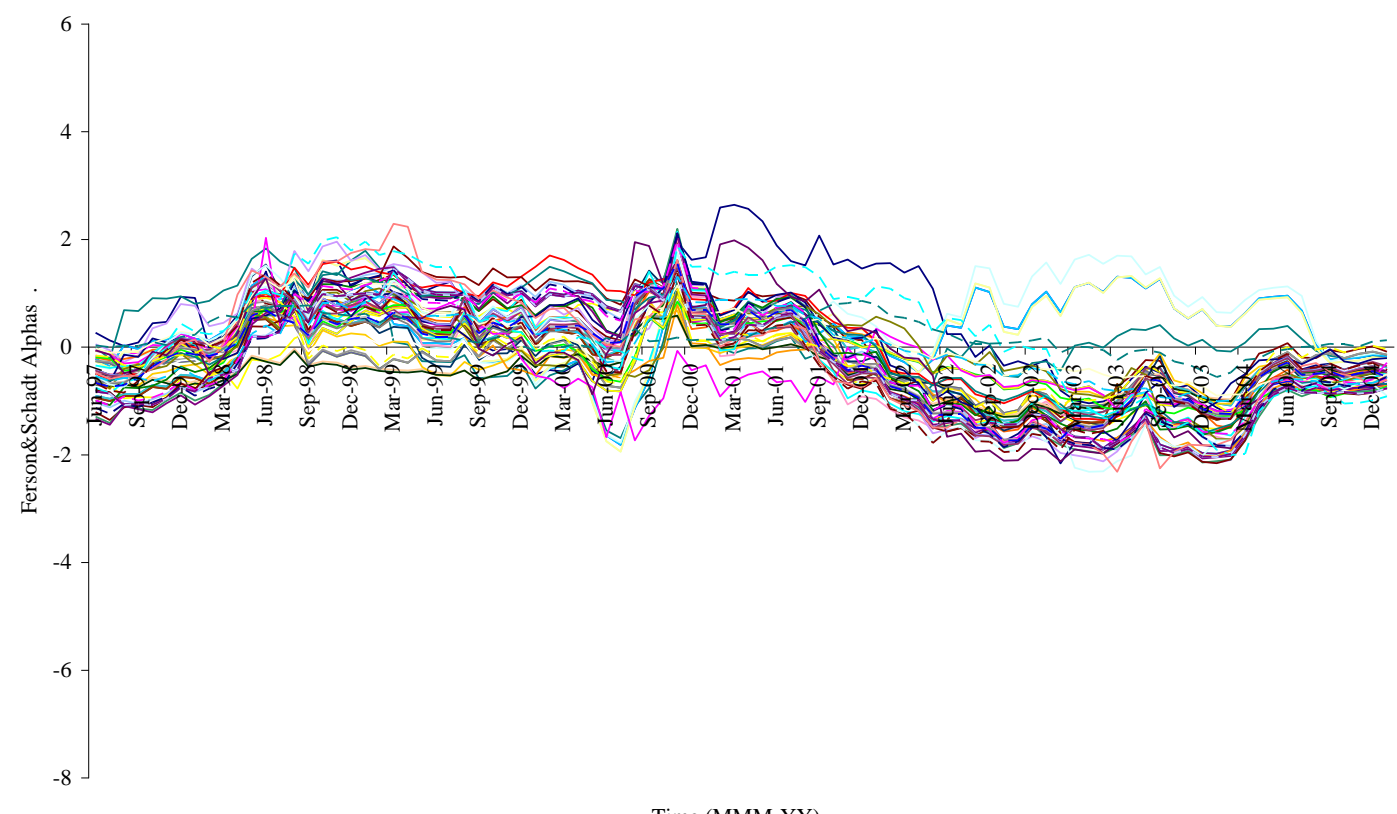

Time (MMM-YY)

Panel B: Rolling alpha t-statistics

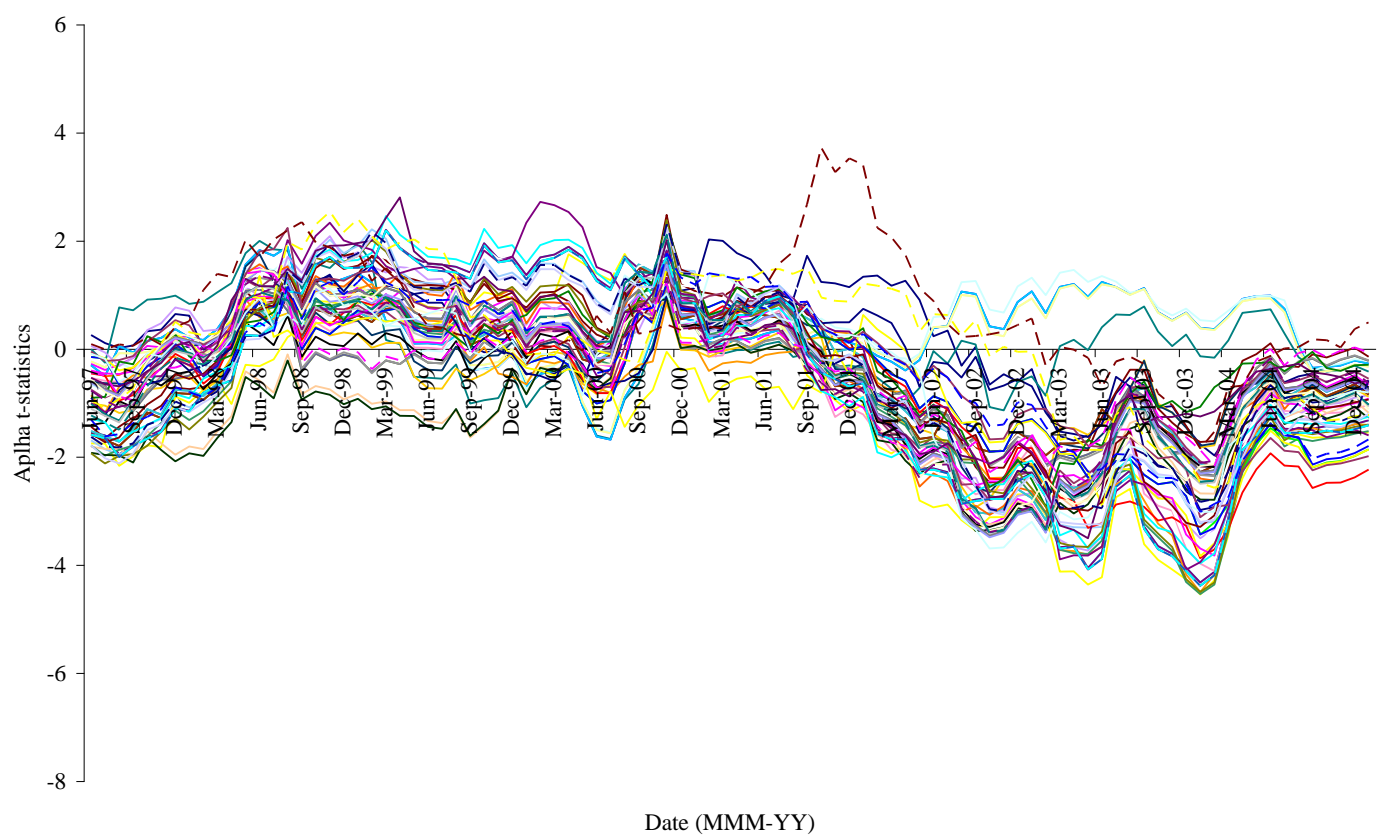

